\title{
A xylose-stimulated xylanase-xylose binding protein chimera created by random nonhomologous recombination
}

Lucas Ferreira Ribeiro ${ }^{1,3}$, Jennifer Tullman ${ }^{1,2}$, Nathan Nicholes ${ }^{1}$, Sérgio Ruschi Bergamachi Silva ${ }^{4}$, Davi Serradella Vieira ${ }^{4}$, Marc Ostermeier ${ }^{1}$ and Richard John Ward ${ }^{5,6^{*}}$

\begin{abstract}
Background: Saccharification of lignocellulosic material by xylanases and other glycoside hydrolases is generally conducted at high concentrations of the final reaction products, which frequently inhibit the enzymes used in the saccharification process. Using a random nonhomologous recombination strategy, we have fused the GH11 xylanase from Bacillus subtilis (XynA) with the xylose binding protein from Escherichia coli (XBP) to produce an enzyme that is allosterically stimulated by xylose.

Results: The PT7T3GFP_XBP plasmid containing the XBP coding sequence was randomly linearized with DNase I, and ligated with the XynA coding sequence to create a random XynA-XBP insertion library, which was used to transform E. coli strain JW3538-1 lacking the XBP gene. Screening for active XBP was based on the expression of GFP from the PT7T3GFP_XBP plasmid under the control of a xylose inducible promoter. In the presence of xylose, cells harboring a functional XBP domain in the fusion protein (XBP+) showed increased GFP fluorescence and were selected using FACS. The XBP + cells were further screened for xylanase activity by halo formation around xylanase producing colonies (XynA+) on LB-agar-xylan media after staining with Congo red. The xylanase activity ratio with xylose/without xylose in supernatants from the XBP+/XynA+ clones was measured against remazol brilliant blue xylan. A clone showing an activity ratio higher than 1.3 was selected where the $X y n A$ was inserted after the asparagine 271 in the XBP, and this chimera was denominated as XynA-XBP271. The XynA-XBP271 was more stable than XynA at $55^{\circ} \mathrm{C}$, and in the presence of xylose the catalytic efficiency was $\sim 3$-fold greater than the parental xylanase. Molecular dynamics simulations predicted the formation of an extended protein-protein interface with coupled movements between the XynA and XBP domains. In the XynA-XBP271 with xylose bound to the XBP domain, the mobility of a $\beta$-loop in the XynA domain results in an increased access to the active site, and may explain the observed allosteric activation.
\end{abstract}

Conclusions: The approach presented here provides an important advance for the engineering enzymes that are stimulated by the final product.

Keywords: Enzyme engineering, Xylanase, Allosteric regulation, Nonhomologous recombination, Directed evolution, Molecular dynamics simulation

\footnotetext{
*Correspondence: rjward@fmrp.usp.br; rjward@ffclrp.usp.br

${ }^{6}$ Departamento de Química, Faculdade de Filosofia, Ciências e Letras

de Ribeirão Preto, Universidade de São Paulo, Av. Bandeirantes, 3900,

Ribeirão Preto, SP 14040-901, Brazil

Full list of author information is available at the end of the article
} 


\section{Background}

Xylanases (endo-1,4-xylanase, EC 3.2.1.8) are the key enzymes involved in hemicellulose degradation, hydrolyzing the $\beta-1,4$-glycosidic bonds between xylose residues in xylan. Based on the amino acid sequence similarity and 3D-structural homology, xylanases have been grouped in glycoside hydrolase (GH) families GH5, GH8, GH10, GH11, and GH43 (CAZy; http://www.cazy.org/) [1, 2]. More recently, xylanolytic activity in members of the GH30 [3] and GH44 [4] families has also been demonstrated. The GH11 xylanases have been extensively studied as model enzymes for understanding the molecular basis for glycosidase mechanisms in general and also have numerous commercial applications in the paper, food and biofuel industries [1].

The saccharification of lignocellulosic material by xylanases and other glycoside hydrolases is generally conducted at a high concentration of solids to minimize water use in industrial processes, and these conditions inevitably result in the accumulation of high concentrations of the final reaction products. These reaction products frequently inhibit the enzymes that are used in the saccharification process [5-7], and application of classical enzymology tools is not always sufficient to circumvent this problem. For example, in the case of overcoming the inhibition of enzymatic activity against an insoluble substrate by a soluble competitive inhibitor, the addition of more substrate may not result in the recuperation of the reaction velocity since a polymeric substrate with a slow rate of diffusion is not capable of effectively competing for the active site with smaller molecules having higher diffusion rates. Thus, overcoming product inhibition is a prerequisite for the practical use of enzymes in bioprocesses, and a promising approach in the development of biocatalysts with increased efficiency through positive modulation of their enzymatic activity.

Bioengineers have been able to create allosteric couplings between biologically unrelated protein domains using different approaches that are generally based on in vitro protein evolution strategies [8-12]. The majority of these studies have the objective of creating protein switches, where proteins show either active ("on") or inactive ("off") states in response to the binding of an effector molecule. However, in the context of biorefineries aimed at biomass saccharification, it is more important for the enzymes to be active throughout the entire process and switching behavior is focused on maintaining the enzyme in the active state. To improve biocatalysis for biomass conversion we have recently used a semi-rational protein design strategy to insert a xylanase GH11from Bacillus subtilis (XynA) into a xylose binding protein (XBP) to create chimeric enzymes showing allosteric stimulation of catalytic activity by xylose [13]. This demonstrates the possibility of engineering lignocellulolytic enzymes that are stimulated by a specific effector through the combination of a binding domain with a catalytic domain. We have expanded this study using random nonhomologous recombination, and here we present the creation of a chimeric enzyme between xylanase and XBP that presents improved catalytic efficiency in the presence of xylose.

\section{Results and discussion}

\section{Random insertion library construction and screening for xylose stimulation}

We have recently demonstrated that it is possible to use a protein engineering approach commonly applied in the construction of protein switches to create xylanases stimulated by xylose, thereby increasing the catalytic efficiency of these enzymes in conditions under which the enzymatic activity is usually inhibited, such as high concentrations of xylose [13]. In the previous study, the xylanase was inserted into XBP at previously defined structural positions using a semi-rational structure guided strategy. Here, with the objective of finding new configurations between these two domains that enable greater intra molecular communication, the xylanase was inserted in a random manner into the XBP.

Random insertion libraries can be created using dilute concentrations of DNase I to generate a single random double-stranded break in the plasmid-borne acceptor gene [10, 14]. Thus, the Escherichia coli XBP was cloned into plasmid pT7T3GFP to create plasmid pT7T3GFP_XBP that was used as the target for insertion of the xylanase gene (Fig. 1a). The insertions were made at sites created using DNase I under controlled conditions such that each vector copy was linearized by random DNA cleavage and ligated to a XynA coding sequence, resulting in a library of random insertions of xylanase at all nucleotide positions of the plasmid. This "naïve" library was comprised of $2.8 \times 10^{5}$ transformants, of which approximately $60 \%$ contained the xylanase insert. Sequencing of the plasmid DNA from randomly selected colonies revealed that the insertions were distributed throughout the plasmid, and deletions varying from 50 to $543 \mathrm{bp}$ were observed in all the sequenced clones (data not shown). Other studies using DNase I to create random insertion libraries and random circular permutation libraries also have found deletions distributed along the acceptor sequence, and contribute to the sequence variability of the library, potentially generating relevant diversity for the creation of new properties in the chimeric proteins [10, 14-16].

Random plasmid cleavage using DNase I generated insertion sites outside the XBP coding sequence, including frame-shifted and inverted insertions, generating a significant fraction of non-functional constructs, and 
therefore the library creation was combined with a powerful screening system (schematized in Fig. 1b). The initial selection for functional XBP domains by FACS was performed using a gene circuit in which the positive regulation of GFP by xylose was used to detect XBP activity. The promoter regulating the xylF gene encoding the XBP $(x y l F)$ is induced by xylose in a concentration-dependent response [17]. Since the main route for xylose uptake by $E$. coli is via XBP, $x y l F$ induction indicates that the cell harbors a functional XBP. The xylose-uptake deficient E. coli JW3538-1 (in which the genomic copy of $x y l F$ has been knocked out) was transformed with the random insertion library and screened for XBP activity using a gene circuit in which expression of the GFP in pT7T3GFP_XBP is under the control of the xylose inducible promotor of the $x y l F$ (PxylF). In the presence of xylose, increased GFP fluorescence was detected only in those cells harboring a functional XBP [17]. To define the upper and lower limits for detection of the $\mathrm{XBP}+$ population, the vector without a copy of XBP (pT7T3GFP) was used as a negative control and the vector with a copy of the parental XBP (pT7T3GFP_XBP) was used as a positive control (see Additional file 1). A total of 202,151 events detected by FACS were analyzed and the sorted cells were plated on solid selective agar media, from which
$2.09 \times 10^{5}$ colonies were obtained. From this population, 2112 clones were analyzed for xylanase activity in the presence of D-xylose by formation of halos on solid agar plates containing xylan after staining with Congo red, (Fig. 1b; Additional file 1), Of these, $\sim 15 \%$ of the colonies formed halos and were classified as $\mathrm{XBP}+/ \mathrm{XynA}+$. These colonies were inoculated into deep well plates, and xylanase activity in the supernatant was measured both in the presence and absence of xylose (Fig. 1b). Of the $288 \mathrm{XBP}+/ \mathrm{XynA}+$ clones analyzed, $4 \%$ (10 clones) showed a greater than $10 \%$ increase in xylanolytic activity in the presence of xylose (see Additional file 1). The plasmid DNA isolated from the clone that showed the largest positive modulation (35\%) in the presence of xylose was sequenced. In this clone, the xylanase coding sequence was inserted after the N271 in the XBP. In addition, this chimeric construct also contained a deletion of 14 residues (272-285) in the XBP, corresponding to a $\beta$-strand in the $\mathrm{C}$-terminal region of the XBP. This clone was denominated as XynA-XBP271 (Fig. 2).

\section{Biochemical and kinetic characterization}

The parental proteins XynA and XBP together with the Xyn-XBP271 chimera were expressed, purified (Additional file 2), and submitted to biochemical and kinetic

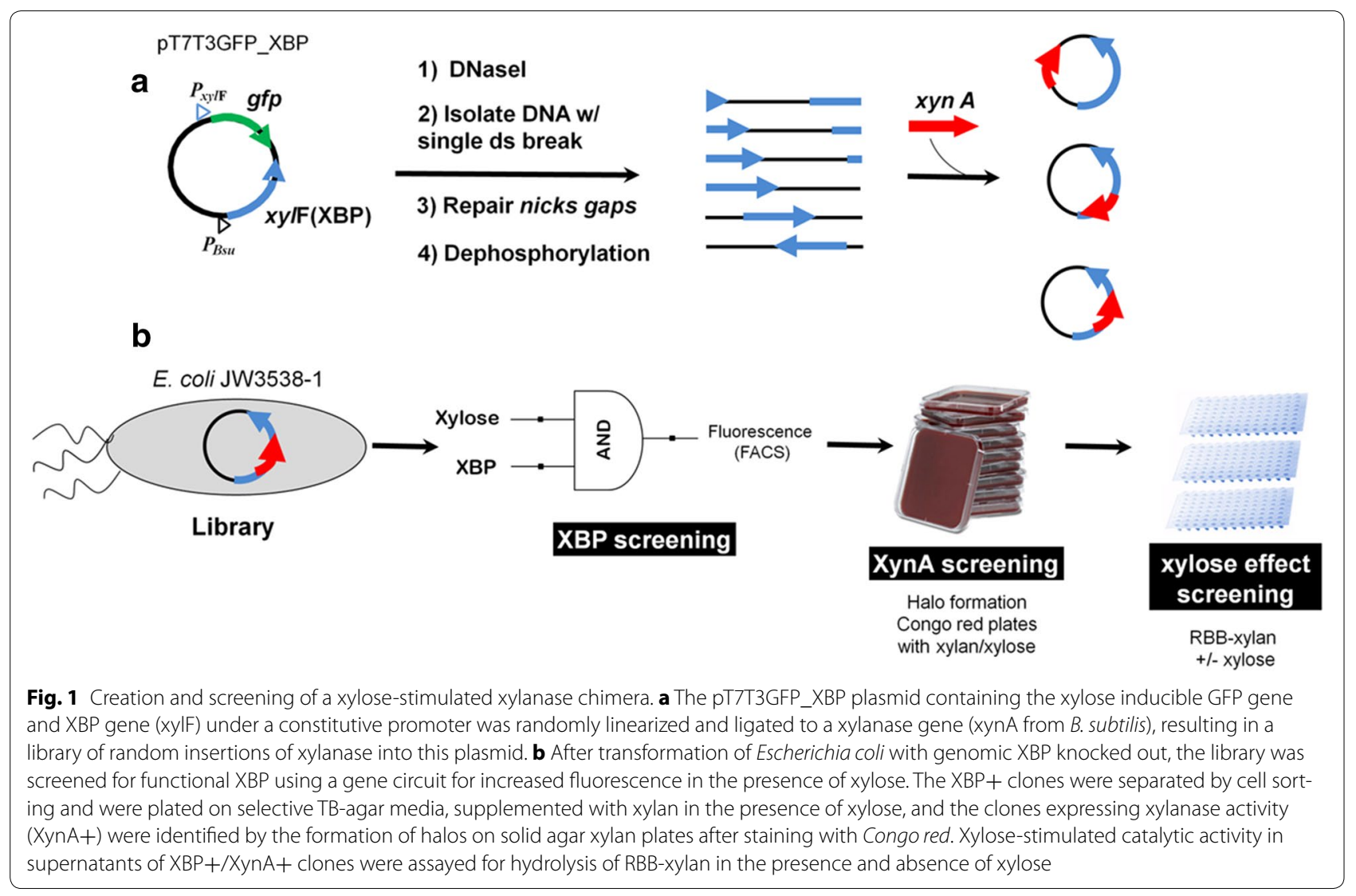




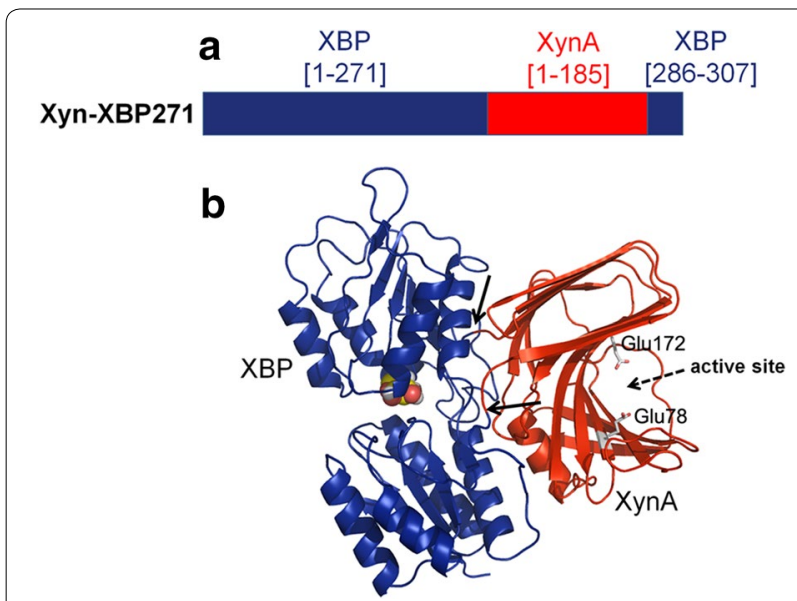

Fig. 2 XynA-XBP chimera presenting the greatest positive modulation by xylose. $\mathbf{a}$ The sequence of the XynA-XBP271 chimera. Regions derived from XBP are shown in blue and those from XynA are shown in red. The number in parentheses indicates the amino acid number of the mature parental proteins. $\mathbf{b}$ Ribbon representation of the final model from molecular dynamics simulations of the XynA-XBP271 chimera. The structure of the xylose-bound XBP is shown in blue, and that from XynA is shown in red. The arrows indicate the xylanase insertion points in the XBP molecule. The active site and catalytic residues Glu78 and Glu172 in the xylanase domain are indicated

characterization. As shown in Fig. 3a, the optimal activity for the hydrolysis of RBB-xylan in MOPS buffer was observed at $\mathrm{pH} 6.5$ both for the parental XynA and for the chimera. Phosphate buffer resulted in a decrease of $\sim 40 \%$ in the activity of the chimeric enzyme at this $\mathrm{pH}$. In $\mathrm{pH} 4.5$ acetate buffer the chimeric enzyme showed greater activity relative to the parental xylanase $($ XynA $=18 \pm 2 \%$; Xyn-XBP271 = $49 \pm 3 \%)$. The chimeric enzyme showed a $48 \%$ increase in activity over the $\mathrm{pH}$ range 4.5-7.5 as compared to the parental XynA.

Both the chimeric enzyme and the parental xylanase showed maximum activity at $45{ }^{\circ} \mathrm{C}$ (Fig. 3b). However, the chimeric enzyme maintained around $85 \%$ activity at $55{ }^{\circ} \mathrm{C}$, while the parental enzyme showed an abrupt decrease (greater than $50 \%$ ) in activity at this temperature. The thermostability of XynA and Xyn-XBP271 was measured at $55{ }^{\circ} \mathrm{C}$ (Fig. 3c). Under these conditions, activity of the parental XynA was reduced by $93 \%$ after 32 minutes. In contrast, the chimeric enzyme retained $61 \%$ activity after 32 minutes and $33 \%$ activity after 128 minutes. The Xyn-XBP271 was shown to be stable with low aggregation of poorly folded proteins observed under the expression conditions used. Previous studies have shown that, in common with other periplasmic binding proteins, XBP has a broad optimal $\mathrm{pH}$ range, from 5.0 to 8.5, and does not suffer alterations in xylose binding capacity in this range [18]. Additionally, XBP has significant thermostability, with a half-life $\left(\mathrm{t}_{1 / 2}\right)$ at $80^{\circ} \mathrm{C}$ of
5 minutes [18], which is greater than the $t_{1 / 2}$ of $2.2 \mathrm{~min}$ utes estimated for XynA at $70{ }^{\circ} \mathrm{C}$ [19]. These characteristics show the $\mathrm{pH}$ and temperature compatibility of XBP with the xylanase domain, and in addition suggest a possible thermal stabilization of the catalytic domain by the fusion with XBP. Recent studies show that the insertion of a less stable domain in a more thermostable domain may be an important strategy to increase the thermostability of the less stable protein [19-22]. Furthermore, it is noteworthy that the fusion with $\mathrm{XBP}$ involves both the $\mathrm{N}$ - and C-terminal regions of the xylanase, and alterations in both these regions are known to influence thermostability of the XynA [23, 24].

The kinetic properties of the purified parental and chimerical enzymes were compared, and Table 1 presents the values for the apparent dissociation constant $\left(K_{\mathrm{RBB} \text {-Xylan }}\right)$, catalytic efficiency $\left(k_{\mathrm{cat}} / K_{\mathrm{RBB}-\mathrm{Xylan}}\right)$ and $n_{\mathrm{H}}$ (Hill coefficient). The value of the $K_{\mathrm{RBB} \text {-Xylan }}$ of the parental xylanase was similar to that of previously reported [13]. An approximate fivefold decrease was observed in the $K_{\mathrm{RBB}-\mathrm{Xylan}}$ value for the XynA-XBP271 in comparison with the parental XynA, although no changes were observed in this parameter after the addition of xylose. The values for the catalytic efficiency $\left(k_{\text {cat }} / K_{\mathrm{RBB}-\mathrm{Xylan}}\right)$ of XynA in the presence of xylose showed a $\sim 15 \%$ decrease (Table 1), as previously reported for this enzyme [13]. However, the observed catalytic efficiency values for the XynA activity in this study were lower than the previously reported values [13], due to differences in the methodology for determination of the enzymatic activity between the two studies. In the absence of xylose, the catalytic efficiency of the chimeric enzyme was $\sim 2 \times$ greater than for the parental XynA. Furthermore, in the presence of xylose, this increase was even more pronounced, reaching $\sim 3 \times$. The catalytic efficiency of the XynA-XBP271 in the presence of xylose was $50 \%$ greater than that observed in the absence of xylose. The chimeric enzyme also presented positive substrate cooperativity with a Hill coefficient $\left(n_{\mathrm{H}}\right)>2.0$. Furthermore, comparison of the changes observed in the kinetic properties resulting from domain insertion for two XynA-XBP chimeras derived from a previous semi-rational fusion study (denoted as XynAXBP2091A and XynA-2621B) [13] reveals an altered $K_{\mathrm{RBB}}$ Xylan value for XynA-XBP271 whereas for the XynA-2621B the main property affected was the $k_{\text {cat }}$ (twofold higher than XynA parental). Moreover, both chimeras showed a similar modulation level in response to xylose (50 \% increase). In the presence of xylose, both the chimeric proteins presented a higher catalytic efficiency in comparison with parental xylanase (threefold increase for XynA-XBP271 and 2.5-fold increase for XynA-2621B). Therefore, these results suggest that both substrate affinity and turnover number can be changed according to the configuration between XynA and XBP domains after fusion. 

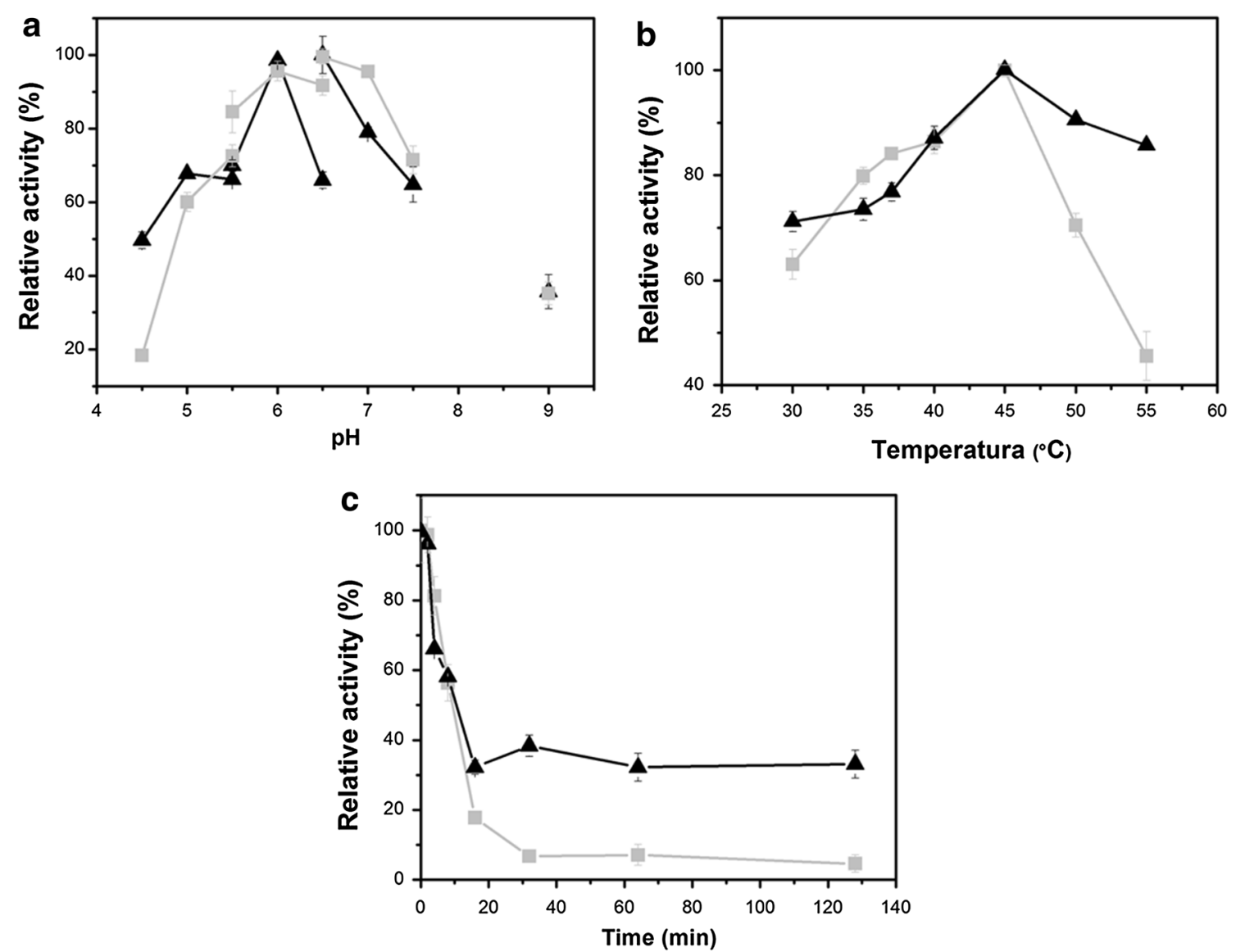

Fig. 3 Biochemical characterization of the xylanase activity of the XynA and the XynA-XBP271 chimera. a The effect of pH. The interconnected points represent the following buffers at a final concentration of $50 \mathrm{mM}$ : acetate (pH 4.5-5.5); phosphate (5.5-6.5), MOPS (pH 6.5-7.5) and arginine$\mathrm{NaOH}\left(\mathrm{pH}\right.$ 9.0). b The effect of temperature, and $\mathbf{c}$ thermal inactivation at $55^{\circ} \mathrm{C}$. The symbols in all graphs are as follows: filled square parental XynA; and filled triangle XynA-XBP271chimera. Error bars show the mean \pm sd

Table 1 Kinetic parameters of the chimeric enzyme compared with the parental enzyme

\begin{tabular}{llllll}
\hline & \multicolumn{2}{l}{ Parental XynA } & & \multicolumn{2}{l}{ Chimera } \\
\cline { 2 - 3 } & -xylose & +xylose & & -xylose & +xylose \\
\hline$K_{\text {RBB-Xylan }}^{a}$ & $1.7 \pm 0.2$ & $1.4 \pm 0.1$ & & $0.33 \pm 0.2$ & $0.33 \pm 0.1$ \\
$K_{\text {cat }} / K_{\text {RBB-Xylan }}^{b}$ & $0.47 \pm 0.03$ & $0.39 \pm 0.02$ & & $0.86 \pm 0.08$ & $1.29 \pm 0.03$ \\
$n_{H}$ & 1.0 & 1.3 & & 2.4 & 2.2 \\
& & & &
\end{tabular}

Data represent the mean \pm SD

a $\mathrm{mg} \mathrm{mL}^{-1}$

${ }^{b} \mathrm{~mL} \mathrm{mg}^{-1} \mathrm{~s}^{-1}$

\section{Enzyme activity against sorghum stover}

The activity of the chimeric enzyme against a natural lignocellulose substrate was evaluated by measuring the total reducing sugar released after treatment of ground sorghum stover with the parental enzyme (XynA), with an equimolar mixture of the XynA $+\mathrm{XBP}$, and with the
XynA-XBP271 chimera (Fig. 4). As expected, since XBP has no catalytic activity, the effect of XynA alone was essentially the same as a mixture of the XynA + XBP. In contrast, the amount of reducing sugar released from sorghum stover by the chimeric enzyme was $37 \%$ greater than the parental XynA enzyme, confirming the increased efficiency of the chimeric enzyme against natural biomass. Although the difference in enzymatic activity between the engineered and parental enzymes was lower with the sorghum stover than with RBB-xylan, this may be due to the complexity and/or architecture of the natural lignocellulosic substrate, which contains 29.1-31.3\% cellulose, 23.9-28.2\% hemicellulose and 7-7.3 \% lignin [25], forming a complex and recalcitrant matrix with an effective pore size that is likely to hinder enzyme access to the xylan substrate. Furthermore, since the XynA releases mainly xylobiose, xylotriose and only a small amount of xylose $[26,27]$, it is possible that in the assay conditions used XynA-XBP271 was not in a fully 


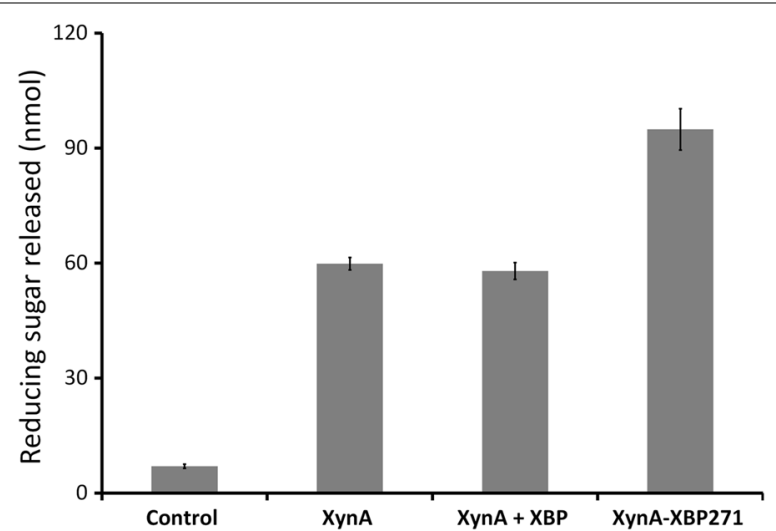

Fig. 4 Reducing sugar release from ground sorghum stover by the XynA and the XynA-XBP271 chimera. The natural lignocellulose substrate was treated with the parental xylanase (XynA), an equimolar mixture of XynA and XBP (XynA + XBP), or the XynA-XBP271 chimera. The control was treated under the same conditions but without enzyme. The result shows total reducing sugar released in nanomoles. Triplicate assays were performed in $100 \mathrm{mM}$ MOPS buffer $(\mathrm{pH} 6.5)$ at $40^{\circ} \mathrm{C}$ for $15 \mathrm{~h}$. Error bars show the mean $\pm \mathrm{sd}$

stimulated state. Thus, to increase xylose release from a natural substrate it is necessary to combine xylanase GH11 with a $\beta$-xylosidase activity [28].

\section{Molecular dynamics simulations}

Molecular dynamics simulations (MDS) suggested the formation and stabilization of a protein-protein interface between the two domains of the XynA-XBP271 chimeric enzyme, both in the presence and absence of xylose (Fig. 5a, b). Similar interdomain protein-protein interfaces were also detected in MDS of the two XynA-XBP chimeras recently described by Ribeiro et al. [13]. The interaction potential energies (IPE) of the interdomain protein-protein interfaces in the XynA-XBP271 in the presence and absence of xylose were calculated and the results are presented in Fig. 5b. Fluctuation of IPE values overtime is a reliable parameter for protein-protein interface analysis $[29,30]$, and the average IPE computed for xylose-bound and free chimeras are $-311.78 \pm 43.74$ and $-270,74 \pm 24.79 \mathrm{kcal} / \mathrm{mol}$, respectively. Comparison of the interaction energies of the interfaces in the XynAXBP271 chimera with those for the 2091A and 2621B chimeras [13], revealed that the interface in the xylose bound XynA-XBP271 chimera is approximately $120 \mathrm{kcal} / \mathrm{mol}$ more stable than the similar interface that is present in the xylose bound XynA-2621B chimera (the most stable interface reported previously [13]). Therefore, the optimization of the interdomain interface as a consequence of binding xylose is strongly dependent on the position in which the xylanase is fused to the XBP. This protein interface in the XynA-XBP271 chimera was investigated in detail using computational alanine scanning to identify the residues that contribute to the stabilization of the interdomain interface. An increase in $\Delta \Delta G_{\text {binding }}$ indicates a destabilization of the interface after introduction of the alanine mutant at the given position and when the $\Delta \Delta G_{\text {binding }}$ values after mutation exceed $1 \mathrm{kcal} / \mathrm{mol}$, the position is considered to be a hot spot for stabilization of the protein-protein interface. For the chimera in the absence of xylose, 35 residues were identified with 8 hot spots, with $\Delta \Delta G_{\text {binding }}$ values varying from 1.1 to $2.9 \mathrm{kcal} / \mathrm{mol}$ (see Additional file 3). For the chimera in the presence of xylose, 52 residues were identified with 17 hotspots hav-

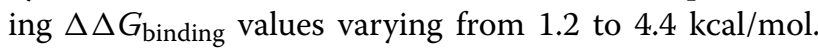
The residues E111 (in the XBP domain), S293 and F319 (in the XynA domain) make significant contribution to the stability of the interface in the xylose bound chimera, with values for $\Delta \Delta \mathrm{G}_{\text {binding }}>3.5 \mathrm{kcal} / \mathrm{mol}$. These residues may be considered the principal hot spots at the interdomain interface, and are of potential importance for the protein-protein interface stabilization.

Polypeptide flexibility was quantitatively analyzed using the root mean square of the fluctuation (RMSF) per residue, using the alpha carbon atoms of each amino acid for the calculations. The calculated RMSF (Fig. 5c) reveals differences in flexibility in the alpha carbon positions when comparing the parental xylanase with the xylanase domain in the XynA-XBP271 chimera in the presence and absence of xylose. Significant fluctuations are observed in the thumb region of the xylanase (between residues 380 and 395) in all structures, and were highest in the parental XynA, less in the XynA-XBP271 without xylose, and lowest in the XynA-XBP271 in the presence of xylose. These results indicate that the fusion of $\mathrm{XBP}$ to the xylanase significantly reduces the flexibility of the thumb region, and that thumb flexibility is further reduced by the binding of xylose to the XBP.

Analysis of the essential movements of the XynAXBP271 chimera can be derived from MDS results, and can provide deeper insights as to the structural and functional differences observed in the presence or absence of xylose. The essential movements can be visualized using a representative structure from MDS in which arrows indicate the direction of atomic movements to highlight large-scale protein motions over the time scale of the simulation (Fig. 5d). Different movements in the xylanase domains were observed in the parental enzyme and the chimera. Previous simulation studies have shown a transition between "open" and "closed" conformations regulated by opposed movements of the thumb and finger domains in the XynA [31, 32]. However, this unique transition was not present in xylanase moiety in the chimeric enzyme, where a twisting movement of the thumb domain relative to the beta-structures in the 

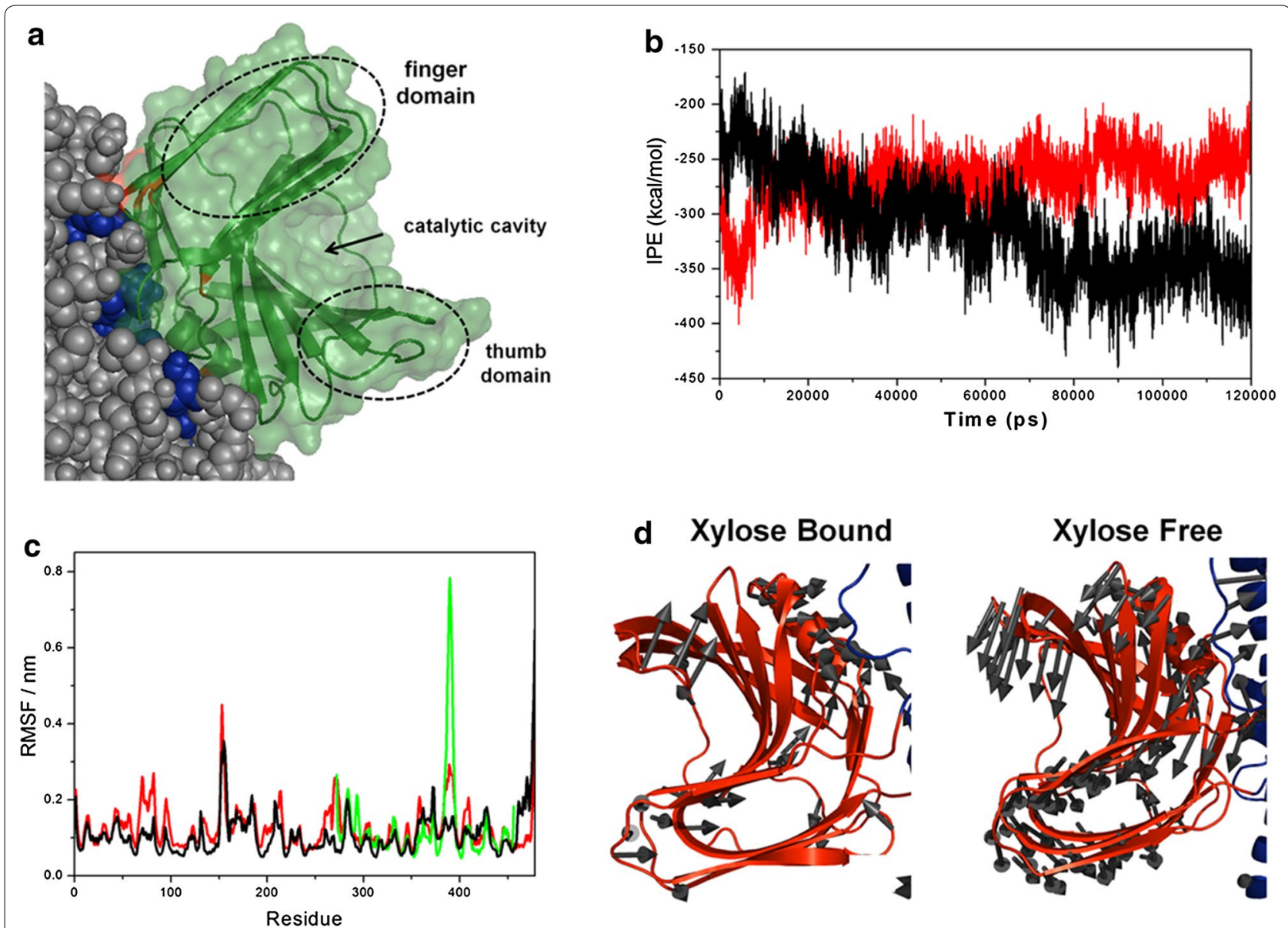

Fig. $5 \mathrm{MD}$ simulations of the XynA-XBP271 chimera. a Representation of the final xylose-bound XynA-XBP271 structure after molecular dynamics simulations. Details of the inter-domain interface are illustrated, where the XynA domain is shown as a cartoon and transparent surface and XBP is shown in a space-filling representation. Hot-spot residues at the protein-protein interface between XBP and XynA are shown in blue (XBP residues) and red (XynA residues). The catalytic site of the XynA is located between the palm and fingers domains, and access to the active site cleft is determined by the orientation of the thumb domain. $\mathbf{b}$ Comparison of the inter-domain interaction potential energy (IPE) as a function of simulation time in the presence (black line) and absence (red line) of xylose in the chimera enzyme. c Local fluctuations (RMSF) of parental XynA (green line) and the XynA-XBP271 chimera in the presence (black line) and absence (red line) of xylose. $\mathbf{d}$ Essential dynamics of the chimeras represented by arrows on an equilibrated representative 3D structure from MDS. The arrows indicate the direction of the local movements of the polypeptide chain in the XynA domain in chimera in the presence and absence of xylose

finger domain was observed. Well-defined thumb movements were observed both in the presence and absence of xylose, however, in the absence of xylose the catalytic cleft in the XynA became more exposed to solvent.

The volume of the active site of the xylanase was calculated using the EPOSPB tool (http://gepard.bioinformatik.uni-saarland.de/software/epos-bp) and the average result obtained for the XynA-XBP271 chimera was $1150 \AA^{3}$, as compared to the value of $860 \AA^{3}$ observed for the parental XynA, demonstrating that the volume of the catalytic site is around $25 \%$ larger in the chimeric xylanase than in the parental enzyme. This calculation suggests that the higher xylanolytic activity observed in the chimera may be the result of increased substrate access to the active site, and is consistent with the reduction in the values of $K_{\mathrm{RBB} \text {-Xylan }}$ observed in the chimeric enzymes (see Table 1 ).

Overall, the MDS results suggest that the XynAXBP271 chimera presents a more rigid structure as compared to the parental XynA and, in particular the thumb region demonstrates a significant reduction in flexibility. The binding of xylose to the XBP domain led to an additional reduction in flexibility, not only in the xylanase domain but in the entire chimera structure. Although binding of xylose reduced the movement of the XBP domain, limiting its structure to the closed conformation that is inherently less flexible, correlated movements in the xylanase domain resulted in an increase 
in the volume of the catalytic cleft, indicating that substrate access to the active site may underly the increase in xylanolytic activity observed in the chimeric enzyme. The allosteric effect in the chimera appears to result from correlated structural changes between the XBP domain and the XynA domain on xylose binding, and the MDS results identify several key residues in the XBP/XynA proteinprotein interface that may be involved in the interdomain communication.

\section{Conclusion}

The combination of protein domains is a powerful evolutionary mechanism for the generation of new architectures and new functions in proteins [33]. Here, using a directed evolution approach, we have combined the non-homologous proteins xylanase and XBP and created chimeric protein XynA-XBP271 with increased catalytic efficiency. The heterotropic effector D-xylose was a positive allosteric modulator of the xylanase domain in the chimera. The approach presented here provides an important advance for the engineering enzymes that are stimulated by the final product.

\section{Methods}

\section{Plasmid construction}

The chromosomal region 3168595-3169587 from E. coli K12 including the signal sequence and the protein coding sequence of the xylF gene encoding the xylose binding protein (XBP) (Gene ID: 948090, $993 \mathrm{nt}$ ) was cloned into the vector pT7T3GFP to construct the plasmid pT7T3GFP_XBP as described previously [17]. The protein coding sequence without the signal sequence from the xynA gene from B. subtilis (GeneID: 939861, $558 \mathrm{nt}$ ) was cloned into the plasmid pT7T3 18U (GeneID: U13869.1; GE Healthcare, Fairfield, Connecticut, USA) using the restriction sites HindIII and BamHI, to generate the construct $\mathrm{pT7T3/XynA.}$

\section{Library creation by random insertion of XynA into XBP}

A random insertion library of xylanase in XBP was created using the protocol developed by Guntas and Ostermeier $[14,15]$ with some modifications. Fifty micrograms of the pT7T3GFP_XBP plasmid was mixed with $50 \mathrm{mM}$ Tris $\mathrm{HCl}$ (pH 7.5), $1 \mathrm{mM} \mathrm{MnCl}_{2}$ and $50 \mu \mathrm{g} / \mathrm{mL} \mathrm{BSA}$, and the volume was completed to $95 \mu \mathrm{L}$ with DNase-free water. Five $\mu \mathrm{L}$ of DNase I (Promega) containing $5 \mathrm{mU}$ of the enzyme was then added. The mixture was incubated for 8 minutes at $22{ }^{\circ} \mathrm{C}$, and the reaction was stopped by the addition of $2.4 \mu \mathrm{L}$ of $0.5 \mathrm{M}$ EDTA and incubation at $75^{\circ} \mathrm{C}$ for $10 \mathrm{~min}$ utes. The DNA from this reaction was purified and eluted in $200 \mu \mathrm{L}$ of water, and a sample of $100 \mathrm{ng}$ of DNA was run on an agarose gel to estimate the percentage of linear DNA. The repair step was then performed in which T4
DNA ligase and T4 DNA polymerase (both enzymes from New England Biolabs, Ipswich, MA, USA) were added in a ratio of 160:1 respectively, per $1 \mu \mathrm{g}$ of linear DNA. The mixture was incubated at $12{ }^{\circ} \mathrm{C}$ for 20 minutes with T4 ligase buffer and $200 \mu \mathrm{M}$ dNTPs. The reaction was stopped by the addition of $10 \mathrm{mM}$ EDTA and heating to $75{ }^{\circ} \mathrm{C}$ for 15 minutes. The linear DNA (5041 bp) was then purified using agarose gel. Approximately $1.5 \mu \mathrm{g}$ of DNA was dephosphorylated using Antarctic phosphatase 12.5 U (New England Biolabs, Ipswich, MA, USA) in Antarctic phosphatase buffer for 30 minutes at $37^{\circ} \mathrm{C}$.

To create the random insertion library, the $x y n A$ gene without the stop codon was amplified by PCR from the pT7T3/XynA vector using phosphorylated primers and ligated to the gel purified PT7T3GFP_XBP plasmid prepared as described in the previous paragraph. The product of the ligation reaction was purified, concentrated and used to transform electrocompetent kanamycin resistant JW3538-1 E. coli cells that lack the XBP gene [the xylF749(del)::kan strain from the Coli Genetic Stock Center, Yale University, USA, hereafter referred to as $\Delta x y l F]$. After regeneration, the cells were plated on LB-agar containing $34 \mu \mathrm{g} / \mathrm{mL}$ kanamycin and $100 \mu \mathrm{g} /$ $\mathrm{mL}$ ampicillin, on bioassay plates $(245 \times 245 \mathrm{~cm})$. After growth, all the bacterial colonies present on the plates were harvested in storage media [LB $+10 \%$ glycerol $(\mathrm{v} / \mathrm{v})]$ and stored at $-80^{\circ} \mathrm{C}$.

\section{Screening for the binding activity of XBP}

A $500 \mu \mathrm{L}$ aliquot of cells from the libraries stored at $-80{ }^{\circ} \mathrm{C}$ was used to inoculate $50 \mathrm{~mL}$ of tryptone broth (TB) (10 g tryptone and $5 \mathrm{~g} \mathrm{NaCl}$ per liter) containing $34 \mu \mathrm{g} / \mathrm{mL}$ kanamycin, $100 \mu \mathrm{g} / \mathrm{mL}$ ampicillin and $10 \mathrm{mM}$ xylose. The culture was grown in an orbital shaker at $250 \mathrm{rpm}$ and $37^{\circ} \mathrm{C}$ for $10 \mathrm{~h}$, and the culture was centrifuged. The cell pellet was resuspended in phosphate buffered saline (PBS) to a concentration of $\sim 10^{6}$ cells $\mathrm{mL}^{-1}$, after which the cells were kept on ice. Flow cytometry analysis fluorescent assisted cell sorting (FACS) was performed on a FACSAria cytometer (Becton, Dickinson and Company, East Rutherford, NJ, USA) equipped with a $405 \mathrm{~nm}$ excitation laser and a 530/30 nm bandpass emission filter. For each sample, $10^{4}$ events were collected at a rate of 500-1000 events per second, where data collection and analysis used the FACSDiva software (Version 6.1.1., BD Biosciences, San Jose, CA, USA). Cells transformed with the pT7T3XBP vector were used as the negative control for correction of the auto-fluorescence, and cells transformed with the pT7T3GFP_XBP vector were used as the positive control. Clones that produced higher fluorescence than cells transformed with pT7T3GFP were collected and were denominated as $\mathrm{XBP}+$ clones. 


\section{Screening for xylanolytic activity}

The XBP+ clones separated by FACS were plated on selective LB-agar media. After incubation at $37{ }^{\circ} \mathrm{C}$ for $12 \mathrm{~h}$, individual colonies were transferred to 384-well microplates containing $60 \mu \mathrm{L}$ selective TB media using an automated colony picker (model K6, Kbiosystems, Basildon, Essex, UK). The plates were incubated at $37{ }^{\circ} \mathrm{C}$ for $24 \mathrm{~h}$, and replicated onto $245 \times 245 \mathrm{~mm}$ bioassay plates containing TB-agar media, supplemented with $0.6 \%(\mathrm{~m} / \mathrm{v})$ xylan, $1 \%(\mathrm{~m} / \mathrm{v})$ xylose; $34 \mu \mathrm{g} / \mathrm{mL}$ kanamycin; $100 \mu \mathrm{g} / \mathrm{mL}$ ampicillin. After incubation of the plates at $37{ }^{\circ} \mathrm{C}$ for $24 \mathrm{~h}$, the clones expressing xylanase activity were identified by the formation of halos after staining with Congo red [34], and were denominated as XBP+/ $\mathrm{XynA}+$ clones.

\section{Measurement of xylose stimulated catalytic activity}

The XBP+/XynA+ clones were grown in TB supplemented with $34 \mu \mathrm{g} / \mathrm{mL}$ kanamycin, $100 \mu \mathrm{g} / \mathrm{mL}$ ampicillin for $48 \mathrm{~h}$ in 96-well plates (deep well). The supernatants were analyzed for hydrolysis of Remazol Brilliant Blue Xylan (RBB-xylan, Sigma-Aldrich, St. Louis, Missouri, USA), using a modification of a previously described protocol [35]. Fifty $\mu \mathrm{L}$ of culture supernatant was mixed with $50 \mu \mathrm{L}$ of a solution containing RBB-xylan $(4 \mathrm{mg} / \mathrm{mL})$ in $100 \mathrm{mM}$ acetate buffer (pH 5.5), in the presence or absence of $1 \%(\mathrm{~m} / \mathrm{v}) \mathrm{D}$-xylose (Sigma-Aldrich, St. Louis, Missouri, USA), and incubated at $37{ }^{\circ} \mathrm{C}$ for $12 \mathrm{~h}$. After incubation, the reaction was stopped by the addition of 2 volumes $(200 \mu \mathrm{L})$ of $96 \%(\mathrm{v} / \mathrm{v})$ ethanol. The insoluble material was removed by centrifugation (2000 $\mathrm{g} / 2$ minutes), and the increase in the absorbance of the supernatant was measured at $595 \mathrm{~nm}$. A single clone that showed activity ratio (with xylose)/(without xylose) greater than 1.3 was selected, and nucleotide sequencing indicated that the XynA domain was inserted within the XBP at position 271, and this chimeric enzyme was denominated as XynA-XBP271.

\section{Expression and purification of the recombinant enzymes}

The parental XynA, parental XBP and the chimeric XynA-XBP271 enzyme were expressed in $E$. coli Rosetta $^{\mathrm{TM}}$ (DE3)] transformed with pET28a (+) (Novagen, Billerica, MA, USA) carrying XynA, XBP or XynAXBP271 with a N-terminal His6-tag and grown in HDM medium containing (per liter) $25 \mathrm{~g}$ of yeast extract, $15 \mathrm{~g}$ of tryptone, $1.2 \mathrm{~g}$ of $\mathrm{MgSO}_{4}$, supplemented with $34 \mu \mathrm{g} /$ $\mathrm{mL}$ kanamycin and $40 \mu \mathrm{g} / \mathrm{mL}$ chloramphenicol. The cells were grown at $30{ }^{\circ} \mathrm{C} / 120 \mathrm{rpm}$ to an $\mathrm{OD}_{600}$ of 0.6 . In all the cases, protein expression was induced with $0.5 \mathrm{mM}$ isopropyl-D-thiogalactopyranoside (IPTG) for $5 \mathrm{~h}$ at $20{ }^{\circ} \mathrm{C} / 120 \mathrm{rpm}$. Cells were harvested by centrifugation $\left(8000 g, 4{ }^{\circ} \mathrm{C}, 10\right.$ minutes). Whole-cell extracts were prepared from cell pellets by ultrasonication in $4 \%(\mathrm{v} / \mathrm{v})$ of the original culture volume of lysis buffer $(100 \mathrm{mM}$ HEPES, $300 \mathrm{mM} \mathrm{NaCl}, 0.5 \mathrm{mM}$ phenylmethylsulfonyl fluoride, $1 \%(\mathrm{v} / \mathrm{v})$ Triton X-100, and $20 \mathrm{mM}$ imidazole, $\mathrm{pH}$ 7.5). The cell extracts were cooled on ice and cleared of cell debris by centrifugation $\left(10,000 g, 4{ }^{\circ} \mathrm{C}, 30 \mathrm{~min}\right.$ utes). The supernatants were loaded on an immobilized metal affinity column Ni-NTA (GE Healthcare, Fairfield, Connecticut, USA) pre-equilibrated with a buffer containing $100 \mathrm{mM}$ HEPES, $300 \mathrm{mM} \mathrm{NaCl}$, and $20 \mathrm{mM}$ imidazole ( $\mathrm{pH}$ 7.5). The column was washed with buffer containing $100 \mathrm{mM}$ HEPES (pH 7.5), $300 \mathrm{mM} \mathrm{NaCl}$, and $40 \mathrm{mM}$ imidazole until no further reduction in the $\mathrm{A}_{280}$ was observed. Protein was eluted with $300 \mathrm{mM}$ imidazole, and protein samples were dialyzed against $20 \mathrm{mM}$ Tris- $\mathrm{HCl}(\mathrm{pH} 8.0)$ and $200 \mathrm{mM} \mathrm{NaCl}$ and stored at $4{ }^{\circ} \mathrm{C}$ for further use. The protein concentrations were determined by measurement of the $A_{280}$.

\section{Enzyme activity assays}

The effect of $\mathrm{pH}$ on xylan hydrolysis by the purified enzymes was determined at $40{ }^{\circ} \mathrm{C}$ in $50 \mathrm{mM}$ with $0.2 \%$ (w/v) RBB-xylan substrate (Sigma-Aldrich, St. Louis, Missouri, USA) buffered with one of the following buffer systems: acetic acid/acetate $(\mathrm{pH}$ 4.5-5.5), potassium phosphate (pH 5.5-6.5), MOPS- $\mathrm{NaOH}$ (pH 6.5-7.5) and Arginine- $\mathrm{NaOH}$ ( $\mathrm{pH}$ 9.0). The effect of temperature on xylanase activity was conducted at temperatures between 30 and $55^{\circ} \mathrm{C}$ in $50 \mathrm{mM}$ acetate, $\mathrm{pH}$ 5.5. Thermostability was assessed by incubation of the purified enzymes at $55{ }^{\circ} \mathrm{C}$ and residual activity was measured in aliquots collected at increasing times. The kinetic parameters for xylanase were determined using the RBB-xylan substrate at concentrations ranging from 0.5 to $10 \mathrm{mg} / \mathrm{ml}$, with and without $1 \%(w / v)$ D-xylose (Sigma-Aldrich, St. Louis, Missouri, USA). The reactions were initiated by the addition of $50 \mathrm{nM}$ of the purified enzyme to MOPS buffer $(\mathrm{pH} 6.5)$ at $45{ }^{\circ} \mathrm{C}$. After 15 minutes, the enzyme was inactivated by incubation at $80{ }^{\circ} \mathrm{C}$ for 10 minutes, followed by incubation at $4{ }^{\circ} \mathrm{C}$ for 5 minutes. One hundred microliters of ethanol were then added and the mixture was incubated at $25^{\circ} \mathrm{C}$ for 15 minutes. The samples were centrifuged at $2000 \mathrm{~g}$ for 2 minutes and $90 \mu \mathrm{L}$ of each sample and transferred to a 96-well plate. The absorbance values were measured at $595 \mathrm{~nm}$ and converted to $\mu$ mols of released dye using a RBB-xylan substrate standard curve generated under the same conditions. All enzymatic activities were determined in triplicate and the maximum velocity $\left(V_{\max }\right)$, apparent dissociation constant $\left(K_{\mathrm{RBB}-\mathrm{Xylan}}\right)$, and catalytic constant $\left(k_{\mathrm{cat}}\right)$ were calculated by nonlinear regression fitting of the data to the semilogarithmic form of the Hill equation using the SigrafW software [36]. 


\section{Enzyme assays using sorghum stover}

The activity of enzymes on a natural substrate was evaluated using ground sorghum stover, previously washed with $100 \mathrm{mM}$ MOPS buffer ( $\mathrm{pH}$ 6.5) to remove residual soluble sugars. A $1 \%(\mathrm{w} / \mathrm{v})$ suspension of the washed substrate was prepared in the same buffer and mixed with either $30 \mathrm{nmol}$ of the purified chimera, $30 \mathrm{nmol}$ of individual purified xylanase or with an equimolar mixture comprised of $30 \mathrm{nmol}$ of xylanase and $30 \mathrm{nmol}$ of $\mathrm{XBP}$, in a final reaction volume of $5 \mathrm{~mL}$. The reaction was incubated at $40{ }^{\circ} \mathrm{C}$ for $15 \mathrm{~h}$ in a temperature controlled orbital shaker at $250 \mathrm{rpm}$ to avoid substrate precipitation, and the total reducing sugar release was measured using the 3,5-dinitrosalicylic acid (DNS) assay [37]. All samples were assayed in triplicate and the mean of the three values was used for subsequent comparisons.

\section{Molecular dynamics simulations and molecular modelling}

Molecular dynamics simulations (MDS) and analyses were performed with the XynA-XBP271 chimera, both with and without bound xylose using the GROMACS 5.0.2 software package [38-40] with the GROMOS96(53A6) force field [41]. The starting atomic coordinates of the chimeras were obtained by comparative protein modeling with program MODELLER 9.13 [42] to merge the XynA (pdb code:1XXN) and the XBP in the open (PDB code: 3M9 W, xylose-free) and closed conformations (PDB code: 3MA0, xylose-bound), respectively. These initial structures were validated using Procheck software [43] with a subsequent energy minimization step using the steepest descent method. The resulting structures were solvated by SPC water molecules at a concentration of approximately $54 \mathrm{~mol} / \mathrm{L}$ in dodecahedron simulation boxes. $\mathrm{Na}^{+}$ions were added to ensure the electroneutrality of the systems. Position restrained dynamics were performed for 400 ps at a reference temperature of $300 \mathrm{~K}$ to improve the equilibration phase. All systems were carried out in the NVT ensemble at neutral $\mathrm{pH}$ and $300 \mathrm{~K}$, with a total time simulation of $120 \mathrm{~ns}$. Temperature was controlled by a V-rescale thermostat [44] and covalent bonds involving hydrogen atoms in the protein and water molecules were restrained by LINCS [45] and SETTLE [46] algorithms, respectively. Newton's equations of motion were solved using the Leap-Frog integration method [47] with $\mathrm{dt}=2.0$ fs. The MaxwellBoltzmann distribution at a reference temperature was employed to generate the initial atomic velocities. The particle-mesh Ewald sum (PME) [48] was used to treat the long-range interactions with a $1.2 \mathrm{~nm}$ cutoff distance. The interaction potential energy (IPE) can be defined as the total interaction energy between protein A and protein $\mathrm{B}$, and was computed according to the equation:

$$
I P E=\sum_{i}^{N A} \sum_{j}^{N B} E_{i, j}
$$

where $E_{i j}$ is the interaction energy between an atom $(i)$ from protein $\mathrm{A}$ and an atom $(j)$ from protein $\mathrm{B}$, and $N A$ and $N B$ are the total number of protein $\mathrm{A}$ and $\mathrm{B}$ atoms, respectively. Computational Alanine Scanning (CAS) was performed using the ROBETTA program [49] to identify "hotspot" residues at the protein-protein interface.

\section{Additional files}

Additional file 1. Screening of the xylose stimulated xylanase/XBP chimera.

Additional file 2. SDS-polyacrylamide gel analysis of the chimeric and parental enzymes purified from recombinant E. coli Rosetta ${ }^{\mathrm{TM}}$ (DE3).

Additional file 3. Hot spot residues at the protein-protein interface between the XBP and XynA domains by molecular dynamics simulations.

\section{Abbreviations}

CAZy: carbohydrate-active enzymes database; GH1 1: glycosyl hydrolase family 11; XynA-XBP271: chimeric enzyme in which the xylanase was inserted after residue 271 of the XBP; pT7T3GFP_XBP: vector used in this work; DNS: 3,5-Dinitrosalicylic acid; PDB: protein data base; IPTG: isopropyl $\beta-D-1-$ Thiogalactopyranoside; MDS: molecular dynamics simulation.

\section{Authors' contributions}

This work is part of the doctoral thesis of LFR, who conducted the library planning and screening, biochemical characterization and data analyses, and drafted the manuscript. JT and NN collaborated in the construction of the random non-homologous recombination library. SRBS and DSV performed the MD simulations, together with analyses and interpretation of the structural data. $\mathrm{MO}$ and RJW participated in the experimental design, coordination of the study, and in revision of the manuscript. All authors read and approved the final manuscript.

\section{Author details}

1 Johns Hopkins University, Baltimore, MD, USA. ${ }^{2}$ Institute for Bioscience and Biotechnology Research, Rockville, MD, USA. ${ }^{3}$ Departamento de Bioquímica e Imunologia, FMRP-Universidade de São Paulo-USP, Ribeirão Preto, SP, Brazil. ${ }^{4}$ Universidade Federal do Rio Grande do Norte, Natal, Brazil. ${ }^{5}$ Laboratório Nacional de Ciência e Tecnologia do Bioetanol-CTBE, Centro Nacional de Pesquisa em Energia e Materiais (CNPEM), Campinas, SP, Brazil. ${ }^{6}$ Departamento de Química, Faculdade de Filosofia, Ciências e Letras de Ribeirão Preto, Universidade de São Paulo, Av. Bandeirantes, 3900, Ribeirão Preto, SP 14040-901, Brazil.

\section{Acknowledgements}

We thank Dr. Rolf Alexander Prade (Oklahoma State University, USA) for providing samples of ground sorghum stover. This work was supported by FAPESP Grant 2010/18850-2 (RJW), FAPESP fellowship 2010/07133-8 (LFR), CNPq Grant 307652/2013-8 (RJW) and National Institute of General Medicine at the National Institutes of Health Grant R01GM066972 (MO).

\section{Availability of supporting data}

Additional files associated with this article are available online.

\section{Competing interests}

The authors declare that no non-financial competing interests exist. MO declares a potential competing interest in the form of issued and pending patent applications on protein switches created by domain insertion. 


\section{Funding}

We thank the International Institute of Physics at Universidade Federal do Rio Grande do Norte for the computer cluster facility. Supported by Conselho Nacional de Desenvolvimento Científico e Tecnológico (CNPq Grant: 473327/2013-9 and 307652/2013-8), FAPESP (project No. 2010/18850-2;RJW, 2010/07133-8 and 2010/10184-3; LFR), and National Institute of General Medicine at the National Institutes of Health Grant R01GM066972 (MO).

Received: 14 March 2016 Accepted: 19 May 2016

Published online: 06 June 2016

\section{References}

1. Collins T, Gerday C, Feller G. Xylanases, xylanase families and extremophilic xylanases. FEMS Microbiol Rev. 2005;29(1):3-23.

2. Lombard V, Ramulu HG, Drula E, Coutinho PM, Henrissat B. The carbohydrate-active enzymes database (CAZy) in 2013. Nucleic Acids Res 2014;42(D1):D490-5.

3. St John FJ, Gonzalez JM, Pozharski E. Consolidation of glycosyl hydrolase family 30: a dual domain 4/7 hydrolase family consisting of two structurally distinct groups. FEBS Lett. 2010;584(21):4435-41.

4. Warner CD, Hoy JA, Shilling TC, Linnen MJ, Ginder ND, Ford CF, et al. Tertiary structure and characterization of a glycoside hydrolase family 44 Endoglucanase from Clostridium acetobutylicum. Appl Environ Microbiol. 2010;76(1):338-46.

5. Teugjas $H$, Valjamae P. Product inhibition of cellulases studied with C-14-labeled cellulose substrates. Biotechnol Biofuels. 2013:6:1.

6. Jonsson LJ, Alriksson B, Nilvebrant NO. Bioconversion of lignocellulose: inhibitors and detoxification. Biotechnol Biofuels. 2013;6:1.

7. Andric P, Meyer AS, Jensen PA, Dam-Johansen K. Reactor design for minimizing product inhibition during enzymatic lignocellulose hydrolysis II. Quantification of inhibition and suitability of membrane reactors. Biotechnol Adv. 2010;28(3):407-25

8. Goodey NM, Benkovic SJ. Allosteric regulation and catalysis emerge via a common route. Nat Chem Biol. 2008;4(8):474-82.

9. Dueber JE, Yeh BJ, Chak K, Lim WA. Reprogramming control of an allosteric signaling switch through modular recombination. Science. 2003;301(5641):1904-8

10. Guntas G, Mansell TJ, Kim JR, Ostermeier M. Directed evolution of protein switches and their application to the creation of ligand-binding proteins. Proc Natl Acad Sci USA. 2005;102(32):11224-9.

11. Jones DD, Edwards WR, Busse K, Allemann RK. Linking the functions of unrelated proteins using a novel directed evolution domain insertion method. Nucleic Acids Res. 2008;36(13):e78.

12. Tullman J, Nicholes N, Dumont MR, Ribeiro LF, Ostermeier M. Enzymatic protein switches built from paralogous input domains. Biotechnol Bioeng. 2015:9999:1-7.

13. Ribeiro LF, Nicholes N, Tullman J, Ribeiro LFC, Fuzo CA, Vieira DS, et al. Insertion of a xylanase in xylose binding protein results in a xylose-stimulated xylanase. Biotechnol Biofuels. 2015;8:1.

14. Guntas G, Ostermeier M. Creation of an allosteric enzyme by domain insertion. J Mol Biol. 2004;336(1):263-73.

15. Guntas G, Mitchell SF, Ostermeier M. A molecular switch created by in vitro recombination of nonhomologous genes. Chem Biol. 2004;11(11):1483-7.

16. Graf R, Schachman HK. Random circular permutation of genes and expressed polypeptide chains: application of the method to the catalytic chains of aspartate transcarbamoylase. Proc Natl Acad Sci USA. 1996;93(21):11591-6.

17. Ribeiro LF, Bressan F, Furtado GP, Meireles F, Ward RJ. D-Xylose detection in Escherichia coli by a xylose binding protein-dependent response. J Biotechnol. 2013;168(4):440-5.

18. Ahlem C, Huisman W, Neslund G, Dahms AS. Purification and properties of a periplasmic D-Xylose-binding protein from Escherichia coli K-12. J Biol Chem. 1982;257(6):2926-31.

19. Ribeiro LF, Furtado GP, Lourenzoni MR, Costa AJ, Santos CR, Nogueira SCP, et al. Engineering bifunctional laccase-xylanase chimeras for improved catalytic performance. J Biol Chem. 2011;286(50):43026-38
20. Kim CS, Pierre B, Ostermeier M, Looger LL, Kim JR. Enzyme stabilization by domain insertion into a thermophilic protein. Protein Eng Des Sel. 2009:22(10):615-23.

21. Furtado GP, Ribeiro LF, Lourenzoni MR, Ward RJ. A designed bifunctional laccase/beta-1,3-1,4-glucanase enzyme shows synergistic sugar release from milled sugarcane bagasse. Protein Eng Des Sel. 2013;26(1):15-23.

22. Pierre B, Labonte JW, Xiong T, Aoraha E, Williams A, Shah V, et al. Molecula determinants for protein stabilization by insertional fusion to a thermophilic host protein. ChemBioChem. 2015;16(16):2392-402.

23. Sun JY, Liu MQ, Xu YL, Xu ZR, Pan L, Gao H. Improvement of the thermostability and catalytic activity of a mesophilic family 11 xylanase by $\mathrm{N}$-terminus replacement. Protein Expres Purif. 2005;42(1):122-30.

24. Wang $\mathrm{Q}$, Xia T. Importance of C-terminal region for thermostability of GH1 1 xylanase from Streptomyces lividans. Appl Biochem Biotechnol. 2008;144(3):273-82

25. Saykhedkar S, Ray A, Ayoubi-Canaan P, Hartson SD, Prade R, Mort AJ. A time course analysis of the extracellular proteome of Aspergillus nidulans growing on sorghum stover. Biotechnol Biofuels. 2012:5:1.

26. Cota J, Oliveira LC, Damasio ARL, Citadini AP, Hoffmam ZB, Alvarez TM, et al. Assembling a xylanase-lichenase chimera through all-atom molecular dynamics simulations. Biochimica Et Biophysica Acta-Proteins Proteom. 2013;1834(8):1492-500.

27. Rhee MS, Wei LS, Sawhney N, Rice JD, St John FJ, Hurlbert JC, et al. Engineering the xylan utilization system in bacillus subtilis for production of acidic xylooligosaccharides. Appl Environ Microbiol. 2014;80(3):917-27.

28. Shallom D, Shoham Y. Microbial hemicellulases. Curr Opin Microbiol. 2003:6(3):219-28

29. Sheinerman FB, Norel $R$, Honig B. Electrostatic aspects of protein-protein interactions. Curr Opin Struct Biol. 2000;10(2):153-9.

30. Sheinerman FB, Honig B. On the role of electrostatic interactions in the design of protein-protein interfaces. J Mol Biol. 2002:318(1):161-77.

31. Murakami MT, Arni RK, Vieira DS, Degreve L, Ruller R, Ward RJ. Correlation of temperature induced conformation change with optimum catalytic activity in the recombinant $\mathrm{G} / 11$ xylanase $A$ from Bacillus subtilis strain 168 (1A1). FEBS Lett. 2005;579(28):6505-10.

32. Vieira DS, Degreve L, Ward RJ. Characterization of temperature dependent and substrate-binding cleft movements in Bacillus circulans family 11 xylanase: a molecular dynamics investigation. Bba Gen Subj. 2009;1790(10):1301-6.

33. Wang ML, Caetano-Anolles G. The evolutionary mechanics of domain organization in proteomes and the rise of modularity in the protein world. Structure. 2009;17(1):66-78.

34. Wood PJ, Erfle JD, Teather RM. Use of complex-formation between congo red and polysaccharides in detection and assay of polysaccharide hydrolases. Method Enzymol. 1988;160:59-74.

35. Biely P, Mislovicova D, Toman R. Remazol brilliant blue xylan—a soluble chromogenic substrate for xylanases. Method Enzymol. 1988;160:536-41.

36. Leone FA, Baranauskas JA, Furriel RPM, Borin IA. SigrafW: an easy-touse program for fitting enzyme kinetic data. Biochem Mol Biol Educ. 2005;33(6):399-403.

37. Miller GL. Use of dinitrosalicylic acid reagent for determination of reducing sugar. Anal Chem. 1959;31(3):426-8.

38. Berendsen HJC, Vanderspoel D, Vandrunen R. Gromacs-a messagepassing parallel molecular-dynamics implementation. Comput Phys Commun. 1995:91(1-3):43-56.

39. Pronk S, Pall S, Schulz R, Larsson P, Bjelkmar P, Apostolov R, et al. GROMACS 4.5: a high-throughput and highly parallel open source molecular simulation toolkit. Bioinformatics. 2013;29(7):845-54

40. Van der Spoel D, Lindahl E, Hess B, Groenhof G, Mark AE, Berendsen HJC GROMACS: fast, flexible, and free J Comput Chem. 2005:26(16):1701-18.

41. Oostenbrink C, Villa A, Mark AE, Van Gunsteren WF. A biomolecular force field based on the free enthalpy of hydration and solvation: the GROMOS force-field parameter sets 53A5 and 53A6. J Comput Chem. 2004:25(13):1656-76.

42. Sali A, Potterton L, Yuan F, Vanvlijmen $H$, Karplus M. Evaluation of comparative protein modeling by modeler. Proteins Struct Funct Genet. 1995;23(3):318-26.

43. Laskowski RA, MacArthur MW, Thornton JM. Validation of protein models derived from experiment. Curr Opin Struct Biol. 1998;8(5):631-9.

44. Bussi G, Donadio D, Parrinello M. Canonical sampling through velocity rescaling. J Chem Phys. 2007;126(1):014101. 
45. Hess B, Bekker H, Berendsen HJC, Fraaije JGEM. LINCS: a linear constraint solver for molecular simulations. J Comput Chem. 1997;18(12):1463-72.

46. Miyamoto S, Kollman PA. Settle-an analytical version of the shake and rattle algorithm for rigid water models. J Comput Chem. 1992;13(8):952-62.

47. Van Gunsteren WF, Berendsen HJC. A leap-frog algorithm for stochastic dynamics. Mol Simul. 1988;1:173-85.
48. Darden T, York D, Pedersen L. Particle mesh Ewald — an N.Log(N) method for Ewald sums in large systems. J Chem Phys. 1993;98(12):10089-92.

49. Kortemme T, Baker D. A simple physical model for binding energy hot spots in protein-protein complexes. Proc Natl Acad Sci USA. 2002;99(22):14116-21.

\section{Submit your next manuscript to BioMed Central and we will help you at every step:}

- We accept pre-submission inquiries

- Our selector tool helps you to find the most relevant journal

- We provide round the clock customer support

- Convenient online submission

- Thorough peer review

- Inclusion in PubMed and all major indexing services

- Maximum visibility for your research

Submit your manuscript at

www.biomedcentral com/submit 